\title{
POSITIVE MOTHERHOOD AT WORK: THE ROLE OF SUPERVISOR SUPPORT IN RETURN TO WORK AFTER MATERNITY LEAVE
}

\author{
Laura Dal Corso ${ }^{1}$, Francesca Carluccio ${ }^{2}$, Barbara Barbieri ${ }^{3}, \&$ Nicola Alberto De Carlo ${ }^{2}$ \\ ${ }^{1}$ Department of Philosophy, Sociology, Education, and Applied Psychology, University of Padua (Italy) \\ ${ }^{2}$ Department of Human Sciences - Communication, Training, Psychology, LUMSA University of Rome (Italy) \\ ${ }^{3}$ Department of Social Sciences and Institutions, University of Cagliari (Italy)
}

\begin{abstract}
Cognitive factors can strongly influence mothers' well-being. Maternal beliefs about societal expectations, role identity, maternal confidence, and concern about being a good or bad parent threaten maternal well-being, especially if these beliefs are irrational, inflexible, and strict. Moreover, they can negatively influence the critical time of returning to work after maternity leave. As stated by the conservation of resources theory, people may become more irrational when their resources are exhausted, with detrimental effects on individual well-being. To protect and enhance well-being, working mothers should draw upon additional resources, including their organizational contexts. In this regard, a key figure is the supervisor, whose positive behaviours and stable support can improve working mothers' well-being and facilitate their effective return to work after maternity leave.

This study aims at examining the relation between the rigidity of maternal beliefs and well-being (namely, general health, job satisfaction, and job performance), hypothesizing the mediation effect of perceived supervisor support during return to work after maternity leave.

The Rigidity of Maternal Beliefs Scale, the measure for Supervisors to Support Return to Work, and the General Health Questionnaire were used together with a two-item measure for examining job performance and a single-item measure for measuring job satisfaction.

The questionnaire was completed by 216 mothers. We tested the hypotheses by means of structural equation models with latent variables, using the Lisrel 8.80 software.

Findings show that rigidity of maternal beliefs is associated with perceived supervisor support during return to work, which, in turn, is associated with working mothers' general health, job satisfaction, and job performance. Consequently, perceived supervisor support during return to work totally mediates the relations between the rigidity of maternal beliefs and the outcomes considered.

Results underline the centrality of supervisor perceived negative behaviors in sustaining working mothers after the long-term leave, when irrational beliefs regarding motherhood threaten their well-being. Practical implications for HR management are discussed.
\end{abstract}

Keywords: Return to work, working mothers, irrational beliefs, supervisor support, well-being.

\section{Introduction}

New mothers form beliefs about the maternal role on both personal and contextual factors. Social and cultural norms often present maternity as associated with a sort of perfectionism. Also thanks to the contribution of mass media and families, motherhood tends to become an ideology, a stereotype, a set of unrealistic expectations that women have to confront themselves with. Women focus on what society believes good mothers should do, how happy they should be of being parents, how intensive their caregiving should be. If these cognitive factors associated with motherhood become inflexible, they negatively affect mothers' psychological well-being (Smith et al., 2019; Thomason, Flynn, Himle, \& Volling, 2015), in the same way as any other form of perfectionism and irrational beliefs does (Girardi, Falco, De Carlo, Dal Corso, \& Benevene, 2018).

Irrational beliefs also depend on the resources available. As noted by the conservation of resources (COR) theory (Hobfoll, 1989), the fewer resources an individual has at his/her disposal, the more irrational he/she becomes (Hobfoll, Halbesleben, Neveu, \& Westman, 2018). COR theory claims that people are motivated to gain, maintain, and protect their resources. Resources are "objects, personal characteristics, conditions, or energies that are valued by the individual or that serve as a means for 
attainment" (Hobfoll, 1989, p. 516). When resources are threatened, lost, or inadequate in relation to the investments made, people experience stress. Loss of resources threatens individual well-being. Moreover, the primacy of loss principle states that the loss of resources carries more weight than their gain: it not only has a stronger impact on the individual, but it also affects him/her more quickly (Hobfoll et al., 2018). In order to protect against loss of resources, working mothers should try to acquire additional resources.

The work environment can be a valuable and significant source from which to draw new resources. In particular, supervisors -individuals in charge of a team who are responsible for tasks and towards other people's (De Carlo, Dal Corso, Falco, Girardi, \& Piccirelli, 2016) - play a crucial role in affecting employees' well-being (Deshpande \& Gupta, in press; He, Morrison, \& Zhang, 2019; Ng, 2017). They can influence work-related stress levels in various ways: by causing - or preventing - stress through their behaviours, by influencing the impact of work environment, and by supporting the implementation of training activities (Donaldson-Feilder, Yarker, \& Lewis, 2011). Moreover, they influence employees' performance (De Carlo et al., 2016; Rana and Javed, 2019) and job satisfaction (Byza, Dörr, Schuh, \& Maier, 2019; Gahlawat, Phogat, \& Kundu, 2019). Examples of supervisors' supportive behaviours in the return to work process are: communicating regularly with returning employees, discussing the possible changes to their tasks, encouraging collaboration and sense of community within the team, managing emotions, being personally accessible and empathetic, and recognizing employees' contributions to organizational objectives (Munir, Yarker, Hicks, \& Donaldson-Feilder, 2012). Supervisors' behaviours have significant practical implications: behaviours are observable and adjustable, and organizations could design interventions to improve supervisors' skills in promoting well-being. We focus on unsupportive supervisors' behaviours for their relevance in affecting employees' well-being, as stated by the above-mentioned primacy of loss principle.

The study aims at examining the relationship between rigidity of maternal beliefs and well-being in working mothers who have returned to work after maternity leave. In particular, drawing from COR theory, we hypothesize that rigidity of maternal beliefs is positively associated with psychological distress and negatively associated with performance and job satisfaction. Furthermore, we hypothesize that all these relationships are mediated by unsupportive supervisor behaviours during return to work.

\section{Methods}

\subsection{Participants and procedure}

The questionnaire was completed by 216 Italian working mothers. Most of the participants were between 31 and 40 years old $(61.5 \%), 26.8 \%$ were over $40,11.7 \%$ were up to 30 . The levels of education considered are university degree (66.8\%), high school diploma (26.4\%), middle school diploma (3.4\%), and other (3.4\%). 83.8\% were employees, $11 \%$ were self-employed workers, $2.9 \%$ were unemployed, $2.4 \%$ other. $84.7 \%$ of participants had an open-ended contract, $11.6 \%$ a fixed-term contract, and $3.7 \%$ other types of contracts. $51.8 \%$ of working mothers worked part-time. All participants gave their written informed consent before the administration of the questionnaire, in accordance with the Declaration of Helsinki. The study was carried out under the AIP (Associazione Italiana di Psicologia - Italian Association of Psychology) regulations, according to which there was no need for previous ethics approval, because it would not deal with animals or vulnerable groups, would not involve any risk to the participants' well-being, use biomedical devices, or invasive investigation tools. Our study was conducted following the recommendations of the Ethic Committee of Psychology Research of the University of Padua.

\subsection{Measure}

Rigidity of maternal beliefs was assessed with 24 items (Thomason et al., 2015). The scale measured four dimensions: perceptions and societal expectations of mothers (e.g. "I should not feel frustrated with my baby when my baby is difficult"), role identity (e.g. "I would feel guilty if I did not enjoy being a mother"), maternal confidence (e.g. "I feel confident in my ability to raise a happy and healthy baby"), maternal dichotomy (e.g. "If my baby does not sleep well, it is a sign that I am not doing a good job as a mother"). The 7-point response scale ranged from 1 (strongly disagree) to 7 (strongly agree). The Cronbach's alpha for the scale is .76.

Measure for Supervisors to Support Return to Work - Negative Behaviours were assessed through 5 items (Munir et al., 2012), such as "My supervisor lost patience with me when things became difficult". The items were rated on a 5 -point Likert scale $(1=$ strongly disagree; $5=$ strongly agree). The Cronbach's alpha for the scale is .82 .

Psychological distress was measured through the Italian version of the General Health Questionnaire-12 (Fraccaroli, Depolo, \& Sarchielli, 1991). A sample item is "I lost much sleep over 
worry". The items were rated on a 4-point scale $(0=$ not at all; $3=$ much more/less than usual). The Cronbach's alpha for the scale is .88 .

Performance was assessed with two items rated on a 10-point Likert scale (from $10 \%$ to $100 \%$ ). Specifically, participants were asked to evaluate their performance and rate the work objectives achieved in the previous year. A sample item is: "We would kindly ask you to specify, using a percentage, how successful you were in achieving your work goals last year". The Cronbach's alpha for the scale is .73.

Job satisfaction was assessed by asking "How satisfied are you with your working life?". The item was taken from the $\mathrm{Q}_{\mathrm{u}}$-Bo test (De Carlo et al., 2008-2011) and was on a 6-point Likert scale $(1=$ very dissatisfied; $6=$ very satisfied $)$.

\subsection{Statistical analyses}

We tested the hypotheses by means of structural equation models (SEM) with latent variables, using the Lisrel 8.80 software (Jöreksog, \& Sörbom, 2006).

We assessed the model fit, starting with the chi-square test $\left(\chi^{2}\right)$. A model shows a good fit to the data if $\chi^{2}$ is non-significant. Given that $\chi^{2}$ is sensitive to sample size, we considered additional fit indices, in particular the normed fit index (NFI), the standardized root mean residual (SRMR), and the root mean square error of approximation (RMSEA). Values close to or greater than .90 for NFI, values close to or smaller than .10 for SRMR, and values close to or smaller than .08 for RMSEA indicate an acceptable fit (Schermelleh-Engel, Moosbrugger, \& Müller, 2003).

We considered $95 \%$ asymmetric confidence intervals based on the distribution of the multiplication term, to verify the significance of the indirect effects. The purpose was to manage the non-normality derived from the path $a *$ path $b$ multiplication, as recommended by MacKinnon's procedure (PRODCLIN; MacKinnon, Fritz, Williams, \& Lockwood, 2007). If the confidence interval does not contain zero, the indirect effect is significant (MacKinnon, Cheong, \& Pirlott, 2012).

Before testing the model, we excluded participants with missing values. Therefore, the final sample consisted of 188 participants.

\section{Results}

Table 1 presents means, standard deviations, and correlations. The latter provide initial evidence that all variables may be positively associated to each other.

We estimated the hypothesized structural model that shows a good fit to the data, considering $\chi^{2}(3)=4.64, p=20 ; \mathrm{NFI}=.95 ; \mathrm{SRMR}=.04$; RMSEA $=.05$ (Figure 1 ). In the model, rigidity of maternal beliefs is positively associated with supervisor negative behaviours in return to work $(\gamma=.16, p<.05)$. Furthermore, supervisor negative behaviours in return to work are positively associated with psychological distress $(\beta=.30, p<.001)$ and negatively associated with performance $(\beta=-.22, p<.001)$ and job satisfaction $(\beta=-.31, p<.001)$. We then verified the significance of the indirect effects. The asymmetric confidence intervals for the relationships between rigidity of maternal beliefs and the outcomes, through supervisor negative behaviours in return to work, do not contain zero. Consequently, the mediation effects are significant. In particular, the unconventional estimate is $0.89,95 \%$ CI [.05877, 1.68523] for the relationship between rigidity of maternal beliefs and psychological distress. The unconventional estimate is $-.92,95 \%$ CI $[-2.35323,-.01018]$ for the relationship between rigidity of maternal beliefs and performance. The unconventional estimate is $-.08,95 \% \mathrm{CI}[-.17451,-.00946]$ for the relationship between rigidity of maternal beliefs and job satisfaction. Given that direct relationships between rigidity of maternal beliefs and psychological distress, performance, and job satisfaction are not significant, we conclude that supervisor negative behaviours in return to work totally mediate the relationship between rigidity of maternal beliefs and the outcomes.

\section{Discussion}

The study aims at examining the relationship between rigidity of maternal beliefs and well-being (namely, psychological distress, performance, and job satisfaction), hypothesizing the mediation effect of perceived supervisor support during return to work after maternity leave.

Perceptions of societal expectations of mothers (do their beliefs reflect the societal and cultural pressure on women as mothers?), role identity (what are their perceived expectations regarding the maternal role?), maternal confidence (do they feel confident that they can manage maternal responsibilities?), and maternal dichotomy (are they good or bad mothers?) are maternal beliefs that, if rigid, may decrease working mothers' well-being.

Our results highlight the importance of the perception of supervisor supportive behaviours in return to work after maternity leave. Rigid maternal beliefs increase psychological distress and decrease 
performance and job satisfaction, but these effects are due to the mediation of supervisor negative behaviours. Supervisor behaviours in return to work totally mediate the relationships between rigidity of maternal beliefs and well-being. The supervisor behaviours considered are all negative (e.g. losing patience, displaying aggressive reactions, going against mothers' requests for adjustment) because of the salience of these conducts. Therefore, supervisor behaviours connect working mothers' irrational beliefs about maternity on the one hand, and vocational (performance and job satisfaction) and non-vocational (psychological distress) outcomes on the other. Our results confirm the central role of supervisors, whose behaviours are the key to work-related stress or organizational well-being. The practical fallout is that a supervisor who seeks to limit negative behaviours can as a consequence increase working mothers' well-being as well, at the same time limiting the negative effects of the rigidity of maternal beliefs.

Based on our results, training activities would be advisable to strengthen both the personal resources that working mothers use when returning to work and the skills that supervisors and HR managers should apply in supporting the returned employees. The interventions directed to working mothers may focus on resilience, self-efficacy, and negotiation skills (Dal Corso, De Carlo, Carluccio, Girardi, \& Falco, 2019). Trainings for supervisors and HR managers may comprise time and emotion management, communication and positive managerial skills. HR managers should consider setting up external psychological counselling services for both working mothers and supervisors: the former may turn their rigid beliefs into more flexible ones; the latter may adopt a more realistic perspective of the role of the working mother.

The study has some limitations. First, its cross-sectional nature does not allow us to determine the direction and the causality of the relations. Even if strong evidences support our results, future research may choose to conduct longitudinal studies. Second, given that we used only one data-gathering method, future research could take into account different kinds of evaluations such as supervisors' perspectives. Moreover, considering that we only examine supervisors' unsupportive negative behaviours, future research could examine positive inclusive and supportive behaviours, such as planning a phased return to work, explaining any changes to the role, or encouraging a team spirit toward the returned employees. Finally, future research could take into account other sources of support considered important by working mothers, such as colleagues, family, and friends.

Table 1. Means, standard deviations, and correlations among variables.

\begin{tabular}{|c|c|c|c|c|c|c|c|}
\hline & $M$ & $s d$ & RMBS & SSRW-NB & GHQ & JP & JS \\
\hline RMBS & 3.71 & .65 & 1 & & & & \\
\hline SSRW-NB & 1.71 & .82 & $.16^{*}$ & 1 & & & \\
\hline GHQ & 9.40 & 5.88 & .13 & $.30^{* *}$ & 1 & & \\
\hline $\mathbf{P F}$ & 7.35 & 1.62 & 0.08 & $-.23^{* *}$ & $-.54^{* *}$ & 1 & \\
\hline JS & 4.55 & 1.10 & -.10 & $-.29^{* *}$ & $-.23^{* *}$ & -.06 & 1 \\
\hline \multicolumn{8}{|c|}{$\begin{array}{l}\mathrm{RMBS}=\text { rigidity of maternal beliefs; } \mathrm{SSRW}-\mathrm{NB}=\text { supervisor support in return to work }- \text { negative } \\
\text { behaviours; } \mathrm{GHQ}=\text { psychological distress; } \mathrm{PF}=\text { performance; JS = job satisfaction. }\end{array}$} \\
\hline $\begin{array}{l}{ }^{*} p<.05 \\
{ }^{* *} p<.01\end{array}$ & & & & & & & \\
\hline
\end{tabular}

Figure 1. The estimated model.

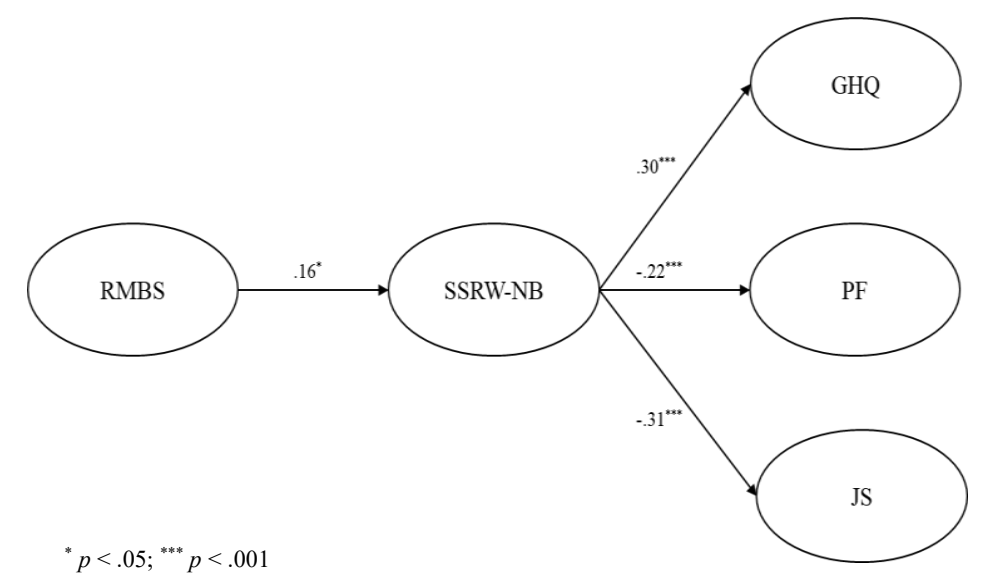




\section{References}

Byza, O.A.U., Dörr, S.L., Schuh, S.C., \& Maier, G.W. (2019). When leaders and followers match: the impact of objective value congruence, value extremity, and empowerment on employee commitment and job satisfaction. Journal of Business Ethics, 158(4), 1097-1112.

Dal Corso, L., De Carlo, A., Carluccio, F., Girardi, D., \& Falco, A. (2019). An opportunity to grow or a label? Performance appraisal justice and performance appraisal satisfaction to increase teachers' well-being. Frontiers in Psychology, 10, 2361.

De Carlo, N. A., Falco, A., \& Capozza, D. (2008/2011). Test di valutazione dello stress lavoro correlato nella prospettiva del benessere organizzativo, $Q_{u}-B o$. Milano: FrancoAngeli.

De Carlo, N.A., Dal Corso, L., Falco, A., Girardi, D., \& Piccirelli, A. (2016). "To be, rather than to seem": The impact of supervisor's and personal responsibility on work engagement, job performance, and job satisfaction in a positive healthcare organization. TPM - Testing, Psychology, Methodology in Applied Psychology, 23(4), 561-580.

Deshpande, A., \& Gupta, R. (in press). Newcomer retention - an investigation on Indian IT industry. Management Decision.

Donaldson-Feilder, E., Yarker, J., \& Lewis, R. (2011). Preventing stress in organizations. How to develop positive managers. Chichester, UK: John Wiley \& Sons.

Fraccaroli, F., Depolo, M., \& Sarchielli, G. (1991). L'uso del General Health Questionnaire di Goldberg in una ricerca su giovani disoccupati [ «The use of Goldberg's General Health Questionnaire in a young unemployed sample»]. Bollettino di Psicologia Applicata, 197, 13-19.

Gahlawat, N., Phogat, R.S., \& Kundu, S.C. (2019). Evidence for life satisfaction among dual-career couples: the interplay of job, career, and family satisfaction in relation to workplace support. Journal of Family Issues, 40(18), 2893-2921.

Girardi, D., Falco, A., De Carlo, A., Dal Corso, D., \& Benevene, P. (2019). Perfectionism and workaholism in managers: The moderating role of workload. TPM - Testing, Psychometrics, Methodology in Applied Psychology, 25(4), 571-588.

He, J., Morrison, A.M., \& Zhang, H. (2019). Improving millennial employee well-being and task performance in the hospitality industry: The interactive effects of HRM and responsible leadership. Sustainability, 11(16), 4410.

Hobfoll, S.E. (1989). Conservation of resources: a new attempt at conceptualizing stress. American Psychologist, 44, 513-524.

Hobfoll, S.E., Halbesleben, J., Neveu, J.P., \& Westman, M. (2018). Conservation of resources in the organizational context: the reality of resources and their consequences. Annual Review of Organizational Psychology and Organizational Behavior, 5, 103-128.

Jöreksog, K.G., \& Sörbom, D. (2006). LISREL 8.80 for Windows. Lincolnwood (IL): Scientific Software International.

MacKinnon, D.P., Cheong, J., \& Pirlott, A.G. (2012). "Statistical mediation analysis", in H. Cooper, P.M. Camic, D.L. Long, A.T. Panter, D. Rindskopf, and K.J. Sher (Eds.), APA Handbook of Research Methods in Psychology, Vol. 2. Research designs: Quantitative, qualitative, neuropsychological, and biological (313-331). Washington DC: American Psychological Association.

MacKinnon, D.P., Fritz, M.S., Williams, J., \& Lockwood, C.M. (2007). Distribution of the product confidence limits for the indirect effect: Program PRODCLIN. Behavior Research Methods, 39(3), 384-395.

Munir, F., Yarker, J., Hicks, B., \& Donaldson-Feilder, E. (2012). Returning employees back to work: developing a measure for supervisors to support return to work (SSRW). Journal of Occupational Rehabilitation, 22, 196-208.

$\mathrm{Ng}$, T.W. (2017). Transformational leadership and performance outcomes: Analyses of multiple mediation pathways. The Leadership Quarterly, 28, 385-417.

Rana, F.A., \& Javed, U. (2019). Psychosocial job characteristics, employee well-being, and quit intentions in Pakistan's insurance sector. Global Business and Organizational Excellence, 38(4), $38-45$.

Schermelleh-Engel, K., Moosbrugger, H., \& Müller, H. (2003). Evaluating the fit of structural equation models: tests of significance and descriptive goodness-of-fit measures. Methods of Psychological Research Online. 8(2), 23-74.

Smith, M.M., Sherry, S.B., Glowacka, M., Speth, T.A., Stewart, S.H., Saklofske, D.H., \& Etherson, M.E. (2019). Who is the most demanding of them all? A multisource investigation of other-oriented perfectionism, socially prescribed perfectionism, and depressive symptoms. Personality and Individual Differences, 138(1), 328-332.

Thomason, E., Flynn, H.A., Himle, J.A., \& Volling, B.L. (2015). Are women's parenting-specific beliefs associated with depressive symptoms in the perinatal period? Development of the rigidity of maternal beliefs scale. Depression and Anxiety, 32, 141-148. 